\title{
Comicidad y sociedad El mundo imaginario de la historieta mexicana
}

GENARO ZALPA RAMÍREZ

Departamento de Sociologia/UAA

1. ¿¿ Or qué la historieta?

Son dos las razones que fundamentan mi interés por el estudio de la historieta mexicana de los años 90: su importancia social y la falta de estudios sobre el tema.

En cuanto a su importancia social, Aurrecoechea y Bartra dicen de la historieta que:

... para tres generaciones de mexicanos, los monitos han sido silabario y cartilla de lectura, lección de historia y fuente de educación sentimental, acceso a mundos exóticos y materia prima de los sueños, satisfacción vicaria de frustraciones económicas, sociales y sexuales. Las historietas han creado mitos y consagrado ídolos, han fijado y dado esplendor al habla popular, han ratificado nuestro machismo y nuestra fe guadalupana. ${ }^{1}$

En un terreno más cuantitativo, Irene Herner ${ }^{2}$ proporciona el dato de que en 1977 se editaban 70 millones de ejemplares de historietas y fotonovelas en México (56 millones de "cuentos" y 14 millones de fotonovelas), es decir, más de un ejemplar por habitante

1. Puros cuentos. La historia de la historieta en México 1874-1934, México, CONACULTA-Grijalbo, 1988, p. 9.

2. Mitos y monitos. Historietas y fotonovelas en México, México, unAM-Nueva Imagen, 1979, p. ix. 
considerando la población del país en ese tiempo. La misma autora, sin embargo, hace la advertencia de que no hay cifras confiables acerca del número de ejemplares publicados. Las instituciones gubernamentales no tienen datos, aunque deberían tenerlos por ley, y los editores algunas veces están interesados en exagerar y otras en minimizar la cantidad de ejemplares publicados. La cifra que da Herner resulta de la extrapolación de datos a partir de una muestra y teniendo en cuenta, también, los datos proporcionados por los editores. Desde entonces, esta cifra ha sido repetida por otros estudiosos, en algunos casos sin citar la fuente, y sin indicar que se refiere a historietas y fotonovelas tomadas en conjunto, como hacen Hinds y Tatum:

Las historietas son inmensamente populares en México. Se venden, quizá, hasta setenta millones de ejemplares al mes. Y hay que tomar en cuenta, también, el mercado de segunda mano. ${ }^{3}$

Para los años noventa no hay datos acerca de la cantidad de historietas que se publican, pero sí se puede decir, con Aurrecoechea y Bartra, que la historieta,

Se lleva en el bolsillo trasero del pantalón o en la bolsa del mandado. Se lee en el camión o en el metro. Se manosea y se tira. Se revende. Se alquila. Pasa de mano en mano. Termina en el fogón o en el cuarto de baño. ${ }^{4}$

En cuanto a los lectores de historietas, Tatum ${ }^{5}$ refiere una conversación tenida con uno de los editores de una de las más populares de los años setenta Lágrimas, Risas y Amor (otras dos son Kalimán y Memín Pinguín) en la que éste les asegura que algunos

3. "Images of women in Mexican Comic Books", Journal of Popular Culture, 18.1, 1984, 146-162, p. 146. Traducción mía.

4. Op. cit., p. 9.

5. "Lágrimas, Risas y Amor: Mexico's Most Popular Romance Comic Book", Journal of Popular culture, 14.3, 1980, 413-423, p. 414. 
médicos, abogados y hombres de negocios han solicitado colecciones completas de la historieta, por lo que concluye que no es cierto que sólo la leen los miembros de las clases más bajas de la sociedad.

Aurrecoechea y Bartra, por su parte, hacen notar que algunos de los lectores de historietas prefieren ocultar el hecho de leerlas. Desde mi punto de vista, los lectores asiduos y legítimos (los que no se ocultan) de las historietas de los años noventa son los miembros de las clases más bajas de la sociedad, con un capital cultural reducido, y no quienes tienen un capital cultural más elevado como, por ejemplo, formación universitaria. Estos últimos pueden ser, en todo caso, lectores casuales de historietas o acostumbrar leer y coleccionar algún tipo de historieta considerada "culta".

El hecho de que los investigadores sociales sean, en su mayoría, personas que no son lectores asiduos de historietas, sino más bien de diarios y revistas, hace que tiendan a sobrevalorar la importancia social de lo que leen, y a infravalorar la de lo que ni ellos ni los conocidos de su entorno social acostumbran leer, como es el caso de las historietas. Uno de los resultados es que haya pocos estudios dedicados a conocer el mundo imaginario de la historieta mexicana, "la gran desconocida" como la llaman Aurrecoechea y Bartra. ${ }^{6}$ $\mathrm{Y}$ otro, que considero importante, es que en muchos estudios se parte de la suposición de que las historietas, como literatura popular, son objetos simples, propios de la simplicidad de sus asiduos lectores que pertenecen, en su mayoría, a las clases populares.

Este estudio, como el de los autores citados, y el de Herner en su momento, está orientado a contribuir con su parte al conocimiento de la historieta mexicana.?

6. Op. cit., Ver también la bibliografía citada por los autores para constatar el exiguo número de estudios sobre la historieta mexicana.

7. Se hace un estudio más completo en Zalpa G., The Imaginary World of Mexican Comics, University of York, Doctoral Thesis, 1996. 


\section{EL CONCEPTO DE IMAGINARIO}

Puesto que se habla del mundo imaginario de la historieta, es necesario especificar lo que se entiende por ese concepto porque, como frecuentemente sucede en las ciencias sociales, no es un concepto unívoco. En realidad, el significado de la palabra imaginario y, por extensión, de la expresión imaginario social, no puede entenderse si no se hace referencia al contexto teórico en el que son empleados. Yo identifiqué, por lo menos, cuatro de estos contextos:

(1) Hay, para empezar, el uso del término en la teoría althusseriana de la ideología. La ideología representa la relación imaginaria (falsa) de los individuos con sus condiciones de existencia. ${ }^{8}$

(2) Hay también la teoría del imaginario social propuesta por Mafesoli, ${ }^{9}$ Durand ${ }^{10}$ y otros. Se presenta como una teoría postmoderna de la cultura, y usa un vocabulario que recuerda a Hegel, Durkheim, la fenomenología y otros autores y corrientes, pero sin identificarse con ninguno. Se puede decir que es una teoría del $h a-$ bitus, sin Bourdieu; de la estructura y la forma, sin el estructuralismo, y una Teología sin Dios (Mafesoli cita a san Pablo cuando dice que Dios es tan difuso y tangible como el aire que respiramos, pero sólo para enfatizar lo que llama la "consagración" del mundo, el imaginario como un sentimiento común). ${ }^{11}$ Puede decirse que usa algunos conceptos sacados de su contexto original para expresar, metafóricamente, la presión vital de lo imaginario, que identifica

8. Althusser, L., Posiciones, México, Grijalbo, 1977.

9. La connaisance ordinaire. Préciss de sociologie compréhensive, Paris, MeridiensKlincksieck, 1985; "The social ambience", Current Sociology, 41.2, 1993, 7-15; La contemplation du monde. Figures de style communautaire, Paris, Bernard Grasset, 1994.

10. "The Implications of the Imaginary and Societies", Current Sociology, 41.2, 1993, 17-32.

11. Michel Mafesoli, "The Social Ambience", Op. cit., p. 8. 
con el sentimiento comunitario: el imaginario es como el Espíritu del tiempo, como la conciencia colectiva, como la religión, como Dios, como la estructura, como la forma, como el habitus, etc. La postmodernidad se concibe como la victoria del espíritu comunitario, y no como la descentralización del sujeto. Es una pérdida de la individualidad, tal como puede observarse en los fanatismos religiosos, los movimientos de masas, la caída de las dictaduras, etc. Todos estos fenómenos se conciben como efectos de la presión del "nosotros".

(3) Hay otro concepto de lo imaginario que puede derivarse de la obra de Berger y Luckmann, La construcción social de la reali$d a d,{ }^{12}$ en la que los autores exponen una teoría de la acción social que considera conocimiento y realidad como sus conceptos centrales, desde una perspectiva constructivista. En esta obra, lo imaginario no se relaciona con la verdad o la falsedad, sino con la realidad y la ficción ${ }^{13}$ o, mejor, con niveles de realidad. De acuerdo a esta teoría, los diferentes objetos se presentan a la conciencia como elementos de diferentes niveles de realidad, siendo punto de referencia la realidad de la vida cotidiana que se organiza en torno al hic et nunc de nuestro tiempo y de nuestro cuerpo y que se considera como la realidad por excelencia. Otras realidades, como las teorías, el teatro, los sueños, los cuentos, etc., se presentan a la conciencia como poseedoras de otros niveles de realidad, no especificados por los autores. En este sentido puede decirse, quizá, que las historietas comparten con otras realidades como las telenovelas, las películas, etc., un nivel similar de realidad que es, en general, menos real que la vida cotidiana. De hecho, las historietas

12. Buenos Aires, Amorrortu, 1976.

13. Ver también Shlomit Rimmon-Kenan, Narrative Fiction. Contemporary Poetics, London, Routledge, 1983; Tzvetan Todorov , Introducción a la literatura fantástica, México, Premiá, 1987; Umberto Eco, Sei passeggiate nei boschi narrativi, Harvard University, Norton Lectures 1992-1993, Milano, Bompiani, 1994. 
son llamadas cuentos en México, mientras que en España se llaman tebeos, y en otros países de América Latina se llaman historietas. Un cuento, especialmente un "cuento de vaqueros", se entiende como una realidad menos real o, de plano, como algo irreal. Con respecto a esto, es importante observar que los niños mexicanos cambian el tiempo de los verbos cuando juegan a ser personajes de historietas: "vamos a jugar a que yo era Supermán y que tú eras Batman", mientras que usan el presente para referirse a su identidad real: "yo soy Pedro, o Juan". Según Eco, ${ }^{14}$ el pretérito imperfecto, que también existe en italiano (pero, por ejemplo, no en inglés) es tan ambiguo que es el tiempo propio de los sueños y de las fábulas. Esto plantea un problema interesante para la teoría de los efectos producidos por los medios en la vida real.

(4) Mi postura se relaciona más estrechamente con el concepto de significaciones imaginarias tal como es empleado por Arnason:

Las significaciones imaginarias son, en los términos más generales, complejos de significado 'que no son el reflejo de lo que se percibe, ni meras extensiones y sublimaciones de tendencias animales, ni estrictamente el desarrollo racional de lo que son los datos (Merleau-Ponty)'. Ellas representan, en otras palabras, un excedente de significado que trasciende todas las determinaciones, fundamentos y presuposiciones. (...) El factor adicional y unificador de sentido que se necesita para imponer coherencia -que no debe confundirse con consistencia lógica o teleológica- ... Esta estructuracion simbólica del significado presupone (...) la capacidad de ver en una cosa lo que no es, de verla de manera diferente a como es (Castoriadis). ${ }^{15}$

Cuando, al interpretar las historietas mexicanas, me refiero a un mundo imaginario que les es propio, me estoy refiriendo a una visión del mundo que se basa en el supuesto de que los mundos físico y social, y sus relaciones, no son percibidos pasivamente, sino que son activamente elaborados para constituir una representación

14. Op. cit., p. 16.

15. Johan P. Arnason, "Culture and Imaginary Significations", Thesis Eleven , 22, 1989, 25-45, Traducción mía. 
del mundo que no es sólo el reflejo mecánico del mundo físico o de una sociedad particular. Mi hipótesis es que hay una forma de representar el mundo que es propia de las historietas mexicanas.

\section{HABITUS Y CULTURA POPULAR}

Hay dos maneras básicas de hacer generalizaciones acerca de los objetos empíricos. La primera consiste en la construcción inductiva de definiciones descriptivas siguiendo el método de combinar características empíricamente observadas de fenómenos que se conciben como similares. La segunda consiste en hacer un análisis que toma en cuenta las complejidades de un objeto construido teóricamente. Estas dos vías las ilustra claramente Lévi-Strauss en su estudio sobre el totemismo. ${ }^{16}$ Primeramente expone cómo el concepto de totemismo fue construido por medio de la yuxtaposición de características que se consideraron como elementos de una institución única, y cómo este concepto desaparece, literalmente se desvanece, cuando se demuestra que esa yuxtaposición es arbitraria y que las características del supuesto totemismo se refieren en realidad a fenómenos diferentes, que se consideraron más similares entre sí de lo que realmente eran. Aún más, Lévi-Strauss compara el caso de la definición "científica" de la histeria con las definiciones del totemismo para demostrar que ambas sugieren una relación de otro orden: parece como si los académicos buscaran, consciente 0 inconscientemente, y bajo el manto de la objetividad científica, hacer a los "pacientes" o a los "primitivos" más diferentes, de la propia conducta o de la propia cultura, de lo que son.

En un segundo momento, en su propio estudio del fenómeno totémico, construye el objeto teóricamente definiéndolo como un caso particular de una actividad humana más general: la inclina-

16. El totemismo en la actualidad, México, Fondo de Cultura Económica, 1965. 
ción a imponer orden, es decir significado, al caos del mundo empírico. El totemismo consiste en relaciones metafóricas, formas concretas y abreviadas de relaciones lógicas. A partir de esto se construye una teoría que da cuenta de la complejidad, de las diferencias, del objeto.

Algo semejante sucede en el estudio de las historietas cuando son definidas como literatura "popular". Este concepto permite una estrategia discursiva que tiende a enfatizar, al mismo tiempo aunque desde puntos de vista diferentes, las semejanzas y las diferencias. Es decir, por una parte la literatura "popular" es vista como más diferente de la literatura "culta" de lo que es. Por otra, se ve como más estandarizada, más simple, más indiferenciada de lo que es, si se toma el punto de vista de comparar entre sí los diferentes productos de la "literatura popular". Es, precisamente, esta supuesta indiferenciación de lo popular, entre otras características que no se analizan aquí, lo que la haría diferente de la literatura culta. Lo anterior se puede observar en el uso que se hace de los conceptos de fórmula y melodrama para caracterizar la literatura 0 , en general, la cultura popular. ${ }^{17}$

El concepto de fórmula en el estudio de la literatura popular fue propuesto, entre otros, por Cawelti en las páginas del Journal of Popular Culture, no sin antes definir una concepción de la cultura popular por comparación con lo que él llama "bellas artes". Las bellas artes son productos diferenciados, únicos y, desde luego, diferentes del arte popular cuya característica es su estandarización:

17. Para un análisis crítico de los conceptos de pueblo y popular, ver Genevieve Bolleme, El pueblo por escrito. Significados culturales de lo popular, México, Grijalbo, 1990; Peter Burke, "The Discovery of Popular Culture" in R. Samuel (ed.) Peoples History and Socialist Strategy, London, Routledge and Kegan Paul, 1981, 216-226; Stuart Hall, "Notes on Deconstructing the Popular" in R. Samuel, Op. cit.., 1981, 227-240; Claude Grignon y Jean-Claude Passeron, Lo culto y lo popular. Miserabilismo y populismo en sociología y en literatura, Madrid, La Piqueta-Endymión, 1990; Pierre Bourdieu, "Vous avez dit populaire?", Actes de la Recherche en Sciences Sociales, 46, 1983, 98-105. 
el análisis de la cultura popular es un tanto diferente del análisis de las bellas artes. Cuando estudiamos las bellas artes estamos interesados esencialmente en el producto único de un artista individual, mientras que en el caso de la cultura popular estamos estudiando un objeto que es, en cierta manera, colectivo. ${ }^{18}$

Según Cawelti, todos los productos culturales contienen una mezcla de dos clases de elementos: convenciones e invenciones, y ambos elementos están presentes en todas las obras de arte, pero las bellas artes tienen más de invenciones y las artes populares tienen más de convenciones. Estas últimas consisten en:

cosas como tramas favoritas, personajes estereotipados, ideas comúnmente aceptadas, metáforas comunes y otras herramientas lingüísticas. ${ }^{19}$

La fórmula, que se define como "un sistema convencional para estructurar productos culturales", ${ }^{20}$ se propone como un instrumento metodológico para analizar los productos de la cultura popular, cuya supuesta indiferenciación los hace particularmente adecuados para ser estudiados con esa herramienta. A manera de ejemplo, el autor aplica el concepto de fórmula al análisis de los westerns:

Un juego de tres equipos que se juega en un campo en el que la línea media es la frontera, y las dos áreas principales son el pueblo y la naturaleza salvaje. Los tres equipos son el grupo de los buenos pobladores que están del lado de la ley y el orden, pero que no tienen suficiente fuerza; los villanos, que rechazan la ley y el orden, pero tienen la fuerza; y el héroe, que tiene ligas con los dos lados. El objeto del juego es hacer que el héroe ponga su fuerza al servicio del grupo de los buenos para destruir a los villanos. ${ }^{21}$

18. John G. Cawelti, "The Concept of Formula in the Study of Popular Literature", Journal of Popular Culture, 3.3, 1969, 381-390, p.382. Traducción mía.

19. Ibid., p. 385. Traducción mía.

20. Ibid., p. 386. Traducción mía.

21. Ibid. p. 390. Traducción mía. 
Si se intenta, sin embargo, aplicar esta descripción al análisis del género, es decir a las películas, novelas e historietas de vaqueros, se encuentra que solamente unos cuantos encajan en la misma. Se tendría, entonces, que concluir, en el caso específico de la historieta, que algunos cuentos de vaqueros no son cuentos de vaqueros porque no se ajustan a la descripción, o que la fórmula no es útil para describir las historietas, y que éstas son más complejas de lo que el concepto de fórmula permite suponer.

En la misma línea, Tatum propone dos fórmulas para comprender las historietas románticas mexicanas, a partir de su estudio de Lágrimas, Risas y Amor:

Fórmula A: 1. El héroe/heroína se enamora de alguien, 2. ese alguien no le corresponde, usualmente porque él/ella no reconoce las cualidades del otro, 3. el amado se casa con, o se enamora de otra persona, 4. el héroe/heroína vive su propia vida y espera pacientemente que el amado/a se de cuenta de su amor, o pierde toda esperanza de unirse algún día con el/la amado/a, 5 . el esposo/a 0 amante del/la amado/a se muere o desaparece de alguna otra forma y 6 . el héroe y la heroína se descubren mutuamente y viven felices para siempre.

Fórmula B: El héroe y la heroína se enamoran desde el principio, pero 2. un obstáculo insuperable se interpone entre ambos y 3 . la aventura termina trágicamente. ${ }^{22}$

También en este caso es fácil demostrar que solamente unas cuantas historietas encajan en esa descripción tan minuciosa. Y, en general, es evidente que la proposición de tales fórmulas, tan particularizadas, se basa en la concepción de la convencionalidad de la literatura popular, es decir, en la idea de que todas las historietas son iguales.

El concepto de melodrama tiene la misma base: la idea de que una receta, más o menos general o detallada, puede aplicarse para

22. Op. cit., p. 416. Traducción mía. 
entender la cultura popular. Thomasseau ${ }^{23}$ cita un panfleto publicado en 1817 que da la receta del melodrama muy detalladamente, y que él mismo sintetiza de la siguiente manera:

1) Convenciones técnicas: a) tres actos, b) dos clases de monólogos, uno para recapitular y otro para conmover, y c) un título llamativo.

2) Temas: a) persecución, b) reconocimiento, c) amor.

3) Personajes: a) el traidor, b) el inocente perseguido, c) el cómico, d) el noble padre, e) el personaje misterioso y f) algunos animales.

4) Moraleja.

Sin embargo, ni siquiera el melodrama clásico corresponde perfectamente a esta descripción. Es importante subrayar que Thomasseau asocia el melodrama con las "clases populares". Según él, estas clases conservan una pasión duradera por el espectáculo de la virtud oprimida y finalmente triunfante. Esta pasión se mantendría posteriormente, cuando la literatura popular, o las telenovelas, son etiquetadas como melodramas. Martín Barbero, ${ }^{24}$ por ejemplo, dice que del teatro el melodrama pasó a la prensa por medio de las novelas de episodios, y posteriormente a la televisión en las telenovelas. Este autor describe el melodrama como sigue:

El melodrama es la razón de que la fuerza que se mueve detrás de la trama sea siempre la ignorancia de una identidad: la ignorancia de un niño acerca de la identidad de sus padres, de un hermano acerca de otro hermano, o de una madre acerca de su hijo. Está presente en la lucha contra las fuerzas del mal y contra las apariencias externas, contra lo que oculta o desvía, es una lucha para ser reconocidos por otros. (...) En Latinoamérica, sea bajo la forma de tango o bolero, cine mexicano o telenovela, el melodrama habla de una

23. Jean-Marie Thomasseau, Le mélodrame, Paris, Presses Universitaires de France, 1984, pp. 20-42.

24. Jesús Martín Barbero, "Memory and Form in the Latin American Soap Opera", in Allen R. C. (ed.) To be continued... Soap Operas Around the World, London and New York, Routledge, 1995, 276-284. 
sociabilidad primaria, cuya metáfora sigue siendo la espesa y censurada trama del apretado tejido de las relaciones familiares. No obstante su devaluación por la economía y la política, esta sociabilidad sigue viviendo culturalmente, y desde su lugar, el pueblo, por medio de la melodramatización de todo, toma su propia forma de venganza sobre la abstracción impuesta por el despojo cultural y la comercialización de la vida. ${ }^{25}$

Una síntesis, hecha por Baldwin, ${ }^{26}$ de la telenovela, Los ricos también lloran, parece confirmar lo dicho por Martín Barbero. Sin embargo, las historietas, que son llamadas frecuentemente melodramas sin más explicación, ${ }^{27}$ no corresponden a esta descripción. Como sucede con el concepto de fórmula, solamente algunos detalles de la descripción, no siempre los mismos, pueden encontrarse en algunas historietas.

Sucede, pues, con los conceptos de fórmula y de melodrama lo mismo que con el concepto inductivo de totemismo: cuando se quieren aplicar a los objetos empíricos, solamente unos cuantos corresponden a algunas de las características consideradas definitorias, hasta que el concepto mismo se desvanece. 0 , como sucede con el concepto de melodrama, se construyen descripciones inductivas ad hoc que corresponden a los objetos de los que se tomaron las características para construir la definición, pero sólo a esos.

El concepto de habitus, por el contrario, no es una descripción inductiva, sino un concepto construido teóricamente para permitir al analista comprender las variaciones de un objeto, haciendo generalizaciones acerca de prácticas que no se conciben como uniformes. No se basa en la convencionalidad de ciertos objetos, como la que supuestamente existe en la cultura popular en oposición a la individualidad de la invención artística. Tomando el ejemplo de las

25. Op. cit., p. 277. Traducción mía.

26. "Montezuma's Revenge. Reading Los Ricos También Lloran in Russia, in Allen R.C., Op. cit., 285-300, p. 286.

27. Irene Herner, Op. cit., p. 125; Aurrecoechea y Bartra, Puros Cuentos. Historia de la historieta en México 1934-1950,México, ConaculTa-Grijalbo, 1993, p. 190. 
relaciones entre el gótico y la escolástica estudiadas por Panofs$\mathrm{ky}^{28}$ las catedrales góticas son diferentes una de otra, como lo son los tratados filosóficos escolásticos unos de otros, y como son diferentes las catedrales góticas de los tratados filosóficos de la escolástica. Sin embargo, un principio teórico, la hipótesis de un habitus consistente, en este caso, en la orientación a imponerles un orden explícito a los objetos -frecuentemente un orden trinitario como manifestación del orden divino- nos permite entender lo que la filosofía escolástica y la arquitectura gótica tienen de común, y por qué coincidieron en el espacio y en el tiempo, sin por eso considerar, ni a una ni a otra, como convenciones indiferenciadas, 0 como expresiones de una fórmula.

De una manera semejante, propongo la hipótesis de un habitus, un principio teórico que ayude a entender la similaridad de las diferencias de las historietas mexicanas: las historietas entendidas como caricaturización del mundo. Entiendo la caricatura como "la exageración, por medio de la simplificación deliberada y, frecuentemente, de la distorsión risible de partes o características" de los objetos (Webster's International Dictionary). Lejos de ser un reflejo inmediato y mecánico del mundo, las historietas recrean el mundo en una forma muy particular, caricaturizándolo. Es como si al entrar al mundo imaginario de los "cuentos", el lector se empezara a mover en un salón con espejos deformantes, ninguno de los cuales refleja la realidad de la misma manera que el otro, pero que tienen todos en común la virtud de deformar la realidad de una manera caricaturesca, la cual, no obstante las distorsiones, sigue siendo reconocible como una realidad particular.

Tal vez lo anterior ayude a entender por qué los analistas de historietas mexicanas han hecho afirmaciones que, por una parte, enfatizan la reproducción de la realidad y, por otra, su falta de vero-

28. Architecture gothique et pensée scolastique, (traducción y postfacio de Pierre Boürdieu), Paris, Minuit, 1967. 
similitud. Según Hinds, ${ }^{29}$ Kalimán, Chanoc, Alma Grande y El Payo, reflejan la sociedad y la cultura mexicanas, pero no describen ningún lugar ni ninguna situación que pueda decirse que son mexicanas: Kalimán es un huérfano , nacido y educado en el Tíbet, y sus poderes se deben a la asistencia de Dios, lo cual está por encima del entendimiento humano. Ixtac, el pueblo de Chanoc, se supone que está poblado por indígenas mayas, pero no lo parecen. Algunos lugares cercanos a Ixtac, además, están poblados por pigmeos o personajes prehistóricos. Ixtac mismo es a veces una ciudad y a veces un pueblo. Los estereotipos femeninos mexicanos no se reflejan en los personajes de El Payo. Y este es el caso también de La Familia Burrón, ${ }^{30}$ cuyos personajes femeninos son demasiado independientes y emprendedores. Para Tatum, ${ }^{31}$ Lágrimas, Risas y Amor refleja la sociedad mexicana de los setenta, pero él mismo dice que es notable que, en términos de características físicas, ninguno de los personajes principales tenga la apariencia física indígena o mestiza, y que las historias no hagan mención de los graves acontecimientos sociales ocurridos por esos años.

Según Herner, los personajes de las historietas no tienen nada que ver con la vida cotidiana y, sin embargo, nunca están completamente desconectados de esa vida:

Excepto en la época de carnaval, sería bastante ridículo si encontráramos caminando por la calle a hombres enfundados en ajustadas mallas, que recuerdan a bailarines y payasos, y cubiertos con capas al estilo de las que usaban los cruzados de la edad media o los vampiros del cine, ni hablar de que llevaran, como tantos héroes de la historieta, antifaces o máscaras. Pero el problema del ridículo en la vida real queda resuelto por el hecho (...) de

29. "Kalimán: A Mexican Superhero", Journal of Popular Culture, 13.2, 1979, 229238; "Chanoc: Adventure and Slapstick on Mexico's Southeast Coast", Journal of Popular Culture, 14.3, 1980, 424-436.

30. Harold Hinds Jr. and Charles Tatum, Op. cit.

31. Op. cit. 
que se trata de personajes de la fantasía. Personajes que habitan el mundo del cuento y de la realidad imaginaria.

Sin embargo, la fantasía nunca está desligada de la realidad cotidiana, sino muy por el contrario, se nutre de ella. ${ }^{32}$

Durante los cuarenta, según Aurrecoechea y Bartra, ${ }^{33}$ las historietas mexicanas pretendieron ser tan reales como la vida real, y usaron el semitono sepia para conseguirlo. La gente decía que los dibujos parecían fotos. El paso siguiente fue usar fotos, combinadas con dibujos, para conseguir un mayor realismo. El resultado, sin embargo, según los mismos autores, estuvo muy lejano del realismo que se pretendía, porque los diseñadores usaron las fotos y el dibujo según una incontrolable ars combinatoria.

Como dije al principio de este artículo, las historietas son llamadas "cuentos" en México. Y "cuento", en la enciclopedia cultural mexicana, significa algo que se opone a lo real. Cuando alguien miente, exagera, o en alguna otra forma se aleja de la verosimilitud, se dice que está contando cuentos. Y, cuando la mentira es muy evidente, que se están contando "cuentos de vaqueros".

Es posible, sin embargo, que la caricaturización del mundo no sea una característica exclusiva de las historietas mexicanas. Foster afirma que la clave de Mafalda consiste en que se basa en estratagemas retóricas o literarias de "juiciosa inverosimilitud". ${ }^{34} \mathrm{Y}$ Woody Allen declara que su película Balas sobre Broadway es una pintura de las noches de Nueva York al modo del comic, es decir "en un estilo exagerado". ${ }^{35}$

En cuanto a las historietas mexicanas de los años noventa, voy a tomar como ejemplo una historia en la que la caricaturización del

32. Op. cit., p. 169.

33. Op. cit., 1993, p. 192.

34. "Mafalda: An Argentina Comic Strip", Journal of Popular Culture, 14.3, 1980. 497-508, p. 498.

35. Proceso, 993, 13 de Noviembre de 1995, p. 71. 
mundo aparece muy evidente. Se trata del número correspondiente al 26 de Septiembre de 1989 del Libro Policiaco: Aventura en San Francisco.

Rafael Márquez, Susana López Avila y Peter Teen, respectivamente Director, Directora Artística y Argumentista del Libro Policiaco de Color, aparecen como personajes de esta historia. Los tres vuelan a San Francisco donde serán recibidos por algunos de los personajes del cuento, miembros de la Golden Gate Police Division. Marcelo Díaz Sánchez, el dibujante peruano, los alcanzará pronto. Pero, ni hace falta decirlo, se embarcan en una aventura policiaca: mientras esperan en el aeropuerto a sus anfitriones, Susana y un pasajero francés con el que está platicando, y quien tiene un portafolios igual al de la mexicana, son secuestrados por dos hombres a punta de pistola. Los bandidos buscaban al pasajero francés únicamente, pero se confunden por el hecho de los portafolios idénticos. El secuestro fue ordenado por un comerciante de joyas robadas, porque esperaba que André Delorme, el francés, tuviera ciertas joyas de las que pensaba apoderarse. Durante su cautiverio, André se enamora de la bella Susana, y muere tratando de defenderla. La Golden Gate Police Division la rescata, captura a los bandidos y revela que André era un agente secreto de la policía francesa. Al final, los editores pueden gozar las celebraciones que han preparado para ellos los de la Golden Gate, y Susana recuerda con cariño a André.

¿Es esta mezcla de fantasía y realidad una estrategia para hacer aparecer como más real el mundo fantástico de las historietas? Podría ser, pero en todo caso el resultado es exactamente el contrario. Quizá un resultado no buscado, pero que se alcanza porque la realidad es caricaturizada en el instante mismo en que se entra al mundo de la historieta. Gráficamente no hay relación con la realidad. Aparte del Golden Gate, la ciudad de San Francisco es cualquier ciudad. No hay diferencia gráfica entre los personajes estadounidenses y los mexicanos. El policía secreto habla un francés muy cómico: "Me ici don marchandise parle, Monsieur", que según la traducción que se proporciona quiere decir: "No sé de que mercancía habla, señor". Todos los personajes femeninos, especialmente Susana, son asombrosamente atractivos, y sus características sexuales se exageran y se exhiben en las situaciones más 
inverosímiles. Se dice que Susana es una mujer mexicana típica, agresiva pero sensacional para hacer el amor, lo cual está muy lejos de la imagen de la mujer mexicana tal como aparece, por ejemplo, en el estudio de Alegría citado por Hinds y Tatum. ${ }^{36}$

Finalmente, sólo en el mundo de la historieta una división de la policía estadounidense homenajea a editores de historietas mexicanas y monta una exposición con sus dibujos.

Hay que decir, sin embargo, que esta hipótesis de la caricaturización de la realidad no elimina la hipótesis de la influencia de las historietas sobre la realidad y viceversa. La hipótesis de la caricaturización sólo pone en claro que las relaciones entre la sociedad y los medios de comunicación, y particularmente las historietas, no son simples, ni directas, ni tan claramente entendibles como algunos autores suponen. ${ }^{37}$ Más bien contribuye a hacer este campo más complejo, ubicando la problemática de las relaciones entre historietas y sociedad en el campo más amplio de las relaciones entre comicidad y sociedad. ${ }^{38}$

\section{LA CONCEPCIÓN DE LA ACCIÓN SOCIAL EN LAS HISTORIETAS MEXICANAS}

En un estudio más amplio ${ }^{39}$ basado en un corpus de 77 historietas, y usando una metodología que combina una versión modificada del esquema actancial propuesto por Greimas con el método de LéviStrauss, se estudia el mundo imaginario de la historieta analizando diferentes temáticas. Aquí se ofrece sólo el análisis de dos de ellas,

36. Op. cit.

37. Ver, en general, los artículos sobre historietas que aparecen en el Journal of $P_{0}$ pular Culture.

38. Ver Umberto Eco, "The Frames of comic Freedom", in Sebeok (de.) Carnival!, Berlin, New York, Amsterdam, Mouton Publishers, 1984, 1-9; V.V. Ivanov, "The Semiotic Theory of Carnival as the Inversion of Bipolar Opposites", in Sebeok, Op. cit., 12-35.

39. Genaro Zalpa, Op. cit. 
basado en un número menor de cuentos, con el propósito principal de mostrar la complejidad con que esas temáticas son tratadas en la historieta.

Empiezo analizando el número 786 de El Libro Sentimental, del 9 de marzo de 1993, que lleva por título ;La Sangre manda!:

Es la historia de Angélica, una niña que es adoptada por un matrimonio que no puede tener hijos, después de que es recogida en un orfanatorio tras la muerte de su madre, y de que su padre, un joven rico que vive con su abuelo porque sus padres han muerto, no quiere saber nada de ella. Posteriormente el padre muere en un accidente en Madrid mientras ejerce su profesión de arquitecto. El abuelo, quien le había aconsejado que se olvidara del producto de su aventura juvenil, al verse solo, busca y encuentra a su bisnieta Angélica, provocando la angustia de los padres adoptivos quienes creen que perderán a su hija. En el final feliz, el abuelo, los padres adoptivos y Angélica deciden vivir como una familia.

A primera vista se puede decir que la transformación narrativa principal es una transformación de estado: la historia de la conjunción de dos personajes, Nazario el bisabuelo y Angélica su bisnieta, sujeto y objeto respectivamente. Una historia precedida o acompañada por otras historias de conjunciones y disyunciones: la disyunción entre Angélica y sus padres naturales, la conjunción entre ella misma y sus padres adoptivos, la disyunción entre 0 scar -el padre de Angélica- y su abuelo Nazario, etc. Sin embargo, un análisis más cuidadoso revela que se trata, más bien, de la narración de la adquisición de un objeto modal, una competencia, por parte de un sujeto operador. Es decir, de la adquisición, por parte de Nazario, de la voluntad para actuar, lo que se concluye no sólo del hecho de que esta historia ocupa el mayor espacio en la historieta, sino también de que las otras transformaciones narrativas se subordinan a esta transformación principal.

La transformación de la voluntad de Nazario es ayudada por otras transformaciones. Una es la historia de una manipulación no exitosa: Una trabajadora social trata, sin lograrlo, de construir una competencia: la conjunción de un posible sujeto operador, el padre 
de Angélica, con un objeto modal, la voluntad de actuar: el deseo de reunirse con su hija. Se opera, sin embargo, otro tipo de transformación modal: La trabajadora social, como emisora de información, hace saber a Oscar que tiene una hija, lo que lo habilita para, a su vez, transmitir la información a su abuelo Nazario. Pero este conocimiento no opera la otra transformación, el deseo de buscar a Angélica: El padre y el bisabuelo saben que tienen un familiar, alguien de su misma sangre, pero este conocimiento no los hace querer reunirse con Angélica.

¿Qué es, entonces, lo que opera el cambio? ¿Es, como el título de la historia parece sugerir, un mandato natural, un mandato de la sangre? ¿ 0 es, más bien, el resultado de una voluntad más o menos libre? Estas preguntas ayudan a hacer una pregunta más general, relacionada con la concepción de la acción social tal como aparece en este cuento.

Antes de continuar, sin embargo, es necesario aclarar que no considero que las historietas sean tratados sociológicos o filosóficos y que, por lo tanto, no pretendo juzgar lo correcto o incorrecto de su concepción de la acción social. Ya es mucho si me atrevo, basado en los elementos proporcionados por el autor, ${ }^{40}$ a hacer una lectura desde esta perspectiva, esperando solamente no caer en una sobreinterpretación arbitraria. ${ }^{41}$

La manera como se hacen las preguntas orienta a buscar las respuestas fuera del modelo actancial, en el nivel paradigmático. Nicks, ${ }^{42}$ siguiendo a Regenstorf, ${ }^{43}$ hace la pregunta en términos de

40. Para la noción de autor, ver Umberto Eco, 1994, Op. cit.

41. Ver, como ejemplo de sobreinterpretación, Ariel Dorfman y Armand Mattelart, Para leer el Pato Donald. Comunicación de masa y colonialismo, México, Siglo XXI, 1980.

42. "Essai d'analyse sémiotique des aventures d'Asterix. Descripction-critiquesperspectives" in Massart, Nicks et Tilleuil (eds.), La bande desinée á l'université... et ailleurs. Etudes sémiotiques et bibliographiques, Louvain-La-Neuve, Université Catholique de Louvain, 1984, 23-186.

43. "Pour une quatrième modalité narrative", Langages, 43, 1976, 71-77. 
por qué, lo que lo lleva a buscar la respuesta en el campo de la motivación. Yo prefiero hacer la pregunta en los términos más simples de qué o quién representa el papel de manipulador, y la respuesta que encuentro es que se trata del mismo Nazario. El mismo personaje representa los papeles de sujeto primero disyunto y luego conjunto con la voluntad de actuar, y de manipulador, personaje que hace hacer, en este caso hace querer. Se trata de una apropiación del objeto modal. Esto, sin embargo, es sólo el inicio de una respuesta porque, si el significado es efecto de las diferencias y las semejanzas, para interpretarlo hay que recurrir a la enciclopedia ${ }^{44}$ de la cultura mexicana, es decir a la forma concreta en que estos términos se relacionan con otros términos en una determinada sociedad, y en esta historia en particular.

"Mandato de la sangre", "la sangre manda", o "la sangre llama" son dichos populares en México. El sentido en que son usados los opone al libre albedrío. Se dice también de los hombres o los animales que "lo llevan en la sangre", para referirse a características que se conciben como naturales. "La sangre manda" se dice cuando se hace referencia a una conducta que se percibe como inevitable y, frecuentemente, inconsciente. Por lo tanto, de acuerdo al título de la historia, uno podría esperar que la sangre fuera, efectivamente, la operadora de la transformación narrativa principal. Y, sin embargo, no es así. La decisión de querer estar unido con Angélica es una decisión personal y libre de Nazario, como la decisión de no querer es una decisión libre tomada por el padre, Oscar. El hecho de que exista una relación de sangre no produce ningún efecto en esta dirección. Parece, incluso, que la relación de sangre es un impedimento, porque una relación de sangre, la de Nazario con Oscar, debe desaparecer para que se opere la transformación modal, el deseo de reunirse con Angélica, mientras que

44. Umberto Eco, Tratado de semiótica general, México, Nueva Imagen, 1978. 
ese deseo se presupone en quienes no tienen una relación de sangre con la niña, los padres adoptivos.

¿Se podría, entonces, concluir que la concepción de la acción social en esta historieta es voluntarista? Quizá se pueda concluir afirmativamente con referencia a esta historia, pero es demasiado pronto para afirmarlo con respecto a las historietas en general.

Como ejemplo contrario puedo citar las historietas que cuentan la intervención de lo sobrenatural en la vida humana, como la historieta con el número 802 de El Libro Sentimental (29 de Agosto de 1989) San Antonio me ayudó en mi orfandad. La protagonista, una bibliotecaria que pierde un libro valioso y es, por ese hecho, amenazada de despido, es milagrosamente ayudada por San Antonio, quien es el operador de las transformaciones que ocurren en esta historia. Lo sobrenatural representa también el papel de operador de la transformación narrativa en la historia de horror $E l$ ataúd macabro (El Libro Rojo, XXI, 1149, 1 de Febrero de 1993): Dos empleados de una funeraria violan y matan a una mujer. Posteriormente ésta se venga, sin que los asesinos puedan hacer nada para impedirlo.

Sin embargo, no siempre que interviene lo sobrenatural se elimina el papel operativo de la acción humana. En Pesadilla interminable (Tinieblas, El Hijo de la Noche, II.43, 5 de Abril de 1993) Tinieblas, un luchador, es el operador que hace que el espíritu de un ser maligno abandone el cuerpo de Faisal, su amigo astrónomo, con la ayuda del signo de la cruz. Lo sobrenatural aparece, aquí, como ayudante, pero no como el operador principal.

Hay, también, un determinismo social. En la historieta Sólo un Apache (El Libro Vaquero, IX.491, 14 de Abril de 1988) un hombre blanco y una mujer apache no pueden vencer los prejuicios sociales que les impiden convertirse en marido y mujer, y prefieren morir antes que separarse.

Todo esto puede resumirse en el análisis de la historieta Padre bebedor, hija del "talón” (¡Ya estuvo suave!, 1.14, 16 de Febrero de 
1995). Es la historia de una muchacha huérfana de madre y con un padre alcohólico, que es obligada por su pobreza a convertirse en prostituta. Después de narrar la historia, el cuento termina con una escena en la que, por casualidad, se encuentran el padre y la hija después de mucho tiempo de no verse. El padre sigue siendo un borracho y la muchacha es ya una prostituta maltratada por la vida. El padre culpa a la pobreza por el destino que les ha impuesto a él y a su hija, pero inmediatamente añade una moraleja: "Pero nosotros somos casi siempre los arquitectos de nuestro propio destino". $\mathrm{Y}$, finalmente, otro personaje, que no es parte de la historia, termina diciendo que está en nuestras manos cambiar un triste destino con trabajo, organización y responsabilidad. Aquí aparecen, pues, tres visiones: la determinación del destino por la pobreza, la libertad de construir nuestro propio destino, y la duda manifestada con la expresión "casi siempre".

Aunque el corpus de historietas analizadas no es el mismo, mi análisis impide universalizar las conclusiones presentadas por Herner en su estudio de las historietas mexicanas de los años setenta. ${ }^{45}$ La autora sostiene que todos los personajes de las historietas mexicanas son presentados como objetos, como productos de relaciones sociales necesarias. Según ella, los únicos personajes que son pintados como sujetos son los que representan a los capitalistas, porque las historietas son el reflejo de la sociedad capitalista.

En el mundo imaginario de la historieta mexicana, al menos la de los años noventa, las cosas no son así. La acción social se concibe a veces como determinada por las circunstancias sociales o lo sobrenatural, pero también a veces como el producto de las acciones libres de los sujetos sociales. Se podría concluir, entonces, que para las historietas, como para las ciencias sociales y la filosofía,

45. Op. cit., pp. 292-301. 
la concepción de la acción social se plantea como un problema y no como una idea clara e invariable. Aunque, como dice LéviStrauss ${ }^{46}$ cuando compara la mitología y la ciencia, los elementos utilizados para alcanzar las respuestas, y las respuestas mismas, sean diferentes.

\section{LA CONCEPCIÓN MORAL}

Otra idea común, otro camino por el que se llega a la conclusión de la simplicidad y la estandarización de las historietas, puede resumirse en la idea de que se trata siempre de una lucha entre el bien y el mal, y que el bien termina siempre por triunfar. ${ }^{47}$

En las historietas analizadas lo que puede apreciarse es una moral casuística, en la que a duras penas pueden individuarse algunos principios de juicio moral. Es decir, acciones y situaciones que se clasifican en una historia como malas, en otra pueden clasificarse como buenas, y en otra como indiferentes moralmente. Por ejemplo, el hecho de ser prostituta se clasifica como malo en la historieta La profesional del amor (El Libro Semanal, XXXIV.1830, 22 de Septiembre de 1989) en la que tal práctica se describe como opuesta a las relaciones matrimoniales y la prostituta se presenta como opuesta a la esposa fiel y devota. En cambio, en la historieta ¡Aleluya, Aleluya, que cada quien agarre la suya! (Sensacional de Barrios, 1.24, 1 de Mayo de 1989) las prostitutas se presentan bajo una luz favorable, como humanas, compasivas y solidarias, opuestas en este caso a las "buenas" esposas, quienes son presentadas como hipócritas. Y en la historieta Hotel "La Comezón" (Historias de hotel en el mundo, 102, 5 de Marzo de 1993) la prostitución es presentada como moralmente indiferente, una especie de juego divertido, o el pretexto para presentar situaciones chuscas.

46. El pensamiento salvaje, México, Fondo de Cultura Económica, 1964, pp. 11-59.

47. Herner, Op. cit., pp. 185-207. 
Igualmente, la iniciativa sexual por parte de las mujeres se presenta como negativa en Era buena para enseñar (¡Así soy...!, III.123, 30 de Noviembre de 1989), como positiva en Las hechiceras (Cuerpos y Almas, V.230, 3 de Marzo de 1993), y como simplemente divertida en Este muerto era muy vivo (Sensacional de futbol, III.117, 22 de Febrero de 1989). La corrupción policiaca se ve como negativa en Fraternidad perversa (Los Poderosos del Camino, II.75, 4 de Enero de 1993) y en iAleluya, Aleluya, que cada quien agarre la suya!, y como solamente divertida en Ni las ricuras de la pescadera me calientan en esta hielera (Sensacional de Mercados, 1.37, 1 de Marzo de 1993).

Los ejemplos son numerosos y, si se leen las historietas con cuidado, pueden añadirse más. Lo que se saca en limpio de todo esto es que si se dice que siempre hay una lucha entre el bien y el mal en las historietas, se está afirmando algo que, por una parte, no es cierto y, por otra, aunque fuera cierto sería banal. Lo interesante, en todo caso, sería conocer cómo es la moral concreta en el mundo imaginario de las historietas, es decir, qué es bueno, qué es malo, y cuáles son los criterios de juicio. Y esto no es tarea fácil. Es decir que los objetos de análisis que parecían, a primera vista, simples, se revelan como muy complejos cuando se someten a un estudio cuidadoso.

El análisis de la historieta jAleluya, aleluya, que cada quien agarre la suya!, puede servir como un ejemplo de lo anterior.

Una muchacha, huérfana y bella, es violada por unos policías que la sorprenden en compañía de unas prostitutas que son sus amigas. Su padrastro, quien es alcohólico, se muestra alegre porque, dice, ahora ya podrá trabajar como prostituta. Esas palabras hacen enojar a su pequeño hermano quien intenta golpear al padrastro, pero es herido por éste. La pobreza, la necesidad de dinero para atender al hermanito y la pérdida de su trabajo como dependienta en una tienda, hacen que la muchacha se decida a trabajar en un cabaret como fichera. Sus amigas prostitutas le ayudan a obtener el trabajo, pero le aconsejan que no siga sus pasos porque, le dicen, aunque ha sido violada, todavía es una buena muchacha. Una de ellas le cuenta que decidió 
seguir el mal camino de la prostitución por un desengaño amoroso, y que después le gustó. Un enfermero que conoce cuando visita a su hermano en el hospital se enamora de ella, pero la deja cuando ella le cuenta de su trabajo en el cabaret. En el, no obstante todo, final feliz, la muchacha y sus amigas celebran la vida, que dicen que es padre después de todo, y la muchacha compara favorablemente a sus amigas con su hipócrita pretendiente.

Hay dos tipos de prácticas sexuales que son consideradas como negativas en esta historia: la violación y la prostitución. La violación es presentada como el resultado de /tener que hacer+no querer hacer/, es decir, de una fuerza externa que se impone a una resistencia activa, que se resuelve en la secuencia narrativa en un /no querer hacerlo/ nunca más. La prostitución, en cambio, en el único caso explicado por una de las prostitutas, es el resultado de un acto libre de transgresión que se resuelve en un /no querer no hacer/ nunca más, es decir la aceptación pasiva de la prostitución. La historieta pasa, después, del juicio de las prácticas al juicio de los personajes, y la muchacha violada es definida positivamente, como opuesta a las prostitutas, bajo un código de moral sexual. Pero al final de la historieta, las mismas prostitutas son definidas como buenas, en oposición al pretendiente, a la luz de otros valores morales que son la comprensión y la solidaridad. Sin embargo, como esta valoración positiva no se dice que se haga "a pesar de" su condición de prostitutas, en esta historia ser prostituta se define, finalmente, como una cualidad /no mala/, una definición que contradice y excluye la definición de la prostitución como /mala/, construyendo así la posibilidad de una definición potencial positiva que, de hecho, no ocurre en esta historia, porque tampoco se define como/buena/. Es suficiente, sin embargo, que se defina como /no mala/ para posibilitar el cambio de código moral de lo sexual a lo social y, por tanto, la valoración positiva de las prostitutas, oponiéndolas al pretendiente, bajo la luz de la comprensión y la solidaridad. 
Si se toman también los ejemplos de las historietas Padre bebedor, hija del "talón", A los setenta años de él se comieron el pastel (¡Así soy!, III.118, 20 de Octubre de 1989), Me vendiste a pesar de ser tu hija (Una Historia, Una Vida, V.229, 5 de Marzo de 1993) y Ojos bellos (Libro Secreto, VI.368, 2 de Septiembre de 1993), en los que las protagonistas son empujadas a la prostitución por sus malas relaciones familiares, es posible, por una parte, dudar de la consistencia de las relaciones familiares que, según Martín Barbero, es una característica del melodrama y, por la otra, sugerir, con toda la cautela de una hipótesis, que el código moral más importante en las historietas mexicanas de los noventa, es la solidaridad social.

\section{PARA CONCLUiR}

Voy a concluir con dos anécdotas personales.

En una ocasión, yendo del Distrito Federal a Ixmiquilpan, Hidalgo, que es un viaje de cerca de tres horas en autobús, me tocó escuchar durante todo el camino una discusión entre dos personas sobre la calidad musical de los conjuntos Los Yonics y Los Solitarios. Quienes discutían lo hacían basándose en argumentaciones detalladas, que sin embargo eran poco comprensibles para mí, que no sería capaz ni siquiera de distinguir a un conjunto del otro si los oyera cantar, porque todos me parecen iguales. En otra ocasión, asistía distraídamente a la Danza de los Moros en el pueblo de Cheranástico en la meseta Purépecha de Michoacán, admirando más bien el conjunto de la fiesta, el colorido de los trajes de los danzantes y del público, etc., que las particularidades de la danza en sí, que para mí se reducían a la repetición monótona de los mismos pasos. Pero me llamó la atención el hecho de que lo que para mí era monotonía, para otro espectador, un indígena al que me dediqué, a la postre, a observar, eran ejecuciones tan diferenciadas que lo llevaron, después de una ohservación detenida de cada uno de 
los ejecutantes, a concluir cuál de ellos era el que mejor bailaba y expresarlo en voz alta. Yo, sin embargo, seguí observando sin ser capaz de notar ninguna diferencia.

Estos episodios me trajeron a la mente lo que hace notar LéviStrauss en El Pensamiento Salvaje: ${ }^{48}$ que para los que somos ignorantes en materia de astronomía, las estrellas son simplemente las estrellas, mientras que los que saben son capaces de diferenciarlas y clasificarlas, detallar sus características, sus distancias de la tierra, sus órbitas, etc. Y también recordé la observación que hace Bourdieu, particularmente en La distinción,${ }^{49}$ acerca de la preparación que se necesita para apreciar las obras que han sido definidas como obras de arte, lo cual no es un don natural.

Esto me llevó a plantearme el problema de si las historietas, y la literatura popular en general, son tan simples como los analistas las consideran: todas iguales, estandarizadas, productos culturales buenos para ser consumidos sólo por el "pueblo". 0 si, por el contrario, es nuestra ignorancia la que nos hace verlas como simples y, por extensión, definir también como simples a sus lectores legítimos.

No quiero sumarme al grupo de los que Eco llama "integrados", ${ }^{50}$ quienes pretenden asimilar la cultura popular, o de masas, con la literatura culta. Aceptando, sin embargo, que las literaturas culta y popular son diferentes, una de las conclusiones que se desprenden de este trabajo es que habría que buscar por otros caminos, no por el de la simplicidad de los contenidos de la literatura popular, estas diferencias. ${ }^{51}$

Otra conclusión es que tampoco la relación entre sociedad e historietas es simple, directa y transparente. La historieta no se limi-

48. Op. cit., p. 13.

49. Madrid, Taurus, 1992.

50. Apocalípticos e integrados ante la cultura de masas, Barcelona:Lumen, 1975.

51. Ver, por ejemplo, Umberto Eco, Sei paseggiate nei boschi narrativi, Op. cit. Especialmente el capítulo 2 . 
ta a copiar la realidad, sino que a partir de los elementos de su entorno, crea su propı mundo imaginario, una visión caricaturesca del mundo, en la que la sociedad se refleja deformada y que, por vías todavía no suficientemente estudiadas, ejerce una influencia sobre lo social.

Y, finalmente, enuncio una conclusión más general que enfatiza la importancia de hacer estudios cuidadosos sobre los objetos de la vida cotidiana, de lo popular, sin asumir como punto de partida una supuesta simplicidad que, en todo caso, debería ser resultado del análisis. 